\title{
Research Article \\ Application of the Visualization through Stereoscopic Glasses in the Massage Therapy
}

\author{
Vladimir Angelov ${ }^{1 *}$ (D) Jana Gotova ${ }^{1}$ (D), Evald Albert ${ }^{1}$ (D), Ognian Tishinov ${ }^{1}$ (D) \\ ${ }^{1}$ National Sports Academy, Studentski Grad, bul. "Academician Stefan Mladenov" 21, Sofia, Bulgaria
}

\author{
Article Information \\ History: \\ Received: May 13, 2018 \\ Accepted: December 9, 2018 \\ Published: February 14, 2019
}

\section{Keywords:}

Pain symptoms

Relaxing effect

Restorative massage

Skin fold

Virtual reality

\begin{abstract}
Objectives: The aim of this paper was the investigation of the relaxation effect after sports restorative massage in standard conditions and in conditions with additional impact by relaxing 3D VR video through stereoscopic glasses. According to the hypothesis of the study, the application of the visualization through stereoscopic glasses during the massage therapy will increase the effect of the massage.

Methods: The contingent of the study was 25 Bulgarian students from the National Sports Academy. The age of the participants was 22-28 years old. The study had three conditions. The first condition included initial registration of the heart rate (HR) of every participant at rest, performance of the massage procedure in standard conditions and final HR fixation. The second condition contained initial HR measurement, combined massage with additional impact of relaxing 3D VR video through stereoscopic glasses and final HR measurement. In the third condition, a musculoskeletal state assessment of the participants was made. On this basis, the contingent for the investigation of the influence of relaxing $3 D$ VR video on the pain symptoms was defined. The measure procedures included HR measurement, skin fold lift test and visual analog scale for assessment of the skin resistance in the affected area and pain sensation survey.

Results: All of the results were with an extremely statistical significance. The heart rate variation before the massage $(74.4 \mathrm{bpm})$, after the massage procedure in normal conditions $(65.7 \mathrm{bpm})$, and after the massage with additional 3D VR visualization $(57.6 \mathrm{bpm})$ was found. Five participants have been diagnosed with resistance and strong pain in the lumbar spine. After a restorative massage with the additional impact of the audio visualization through the virtual reality glasses, painful symptoms were not observed.

Conclusions: The analysis of the results proved the correctness of the hypothesis of the study. The investigation found that the applying relaxing $3 \mathrm{D}$ visualization through stereoscopic glasses during massage therapy leads to increase of the restorative effect and to the reduction of the pain symptoms.
\end{abstract}

\section{INTRODUCTION}

$\mathrm{T}$ he massage therapy can be examined as a tool for restoration, activation and recreation. This therapy has a wide application in sport. The development of the massage techniques is implemented in two directions: east and west. According to many studies, both directions have a positive effect on the human life [1-9]. Eastern massage therapy is based on the impact on biologically active points and energy meridians $[1,4-6,9]$. The Western massage therapy uses mas-

*Correspondence: Vladimir Ivanov Angelov, National Sports Academy, Studentski Grad, bul. Academician Stefan Mladenov 21, Sofia, Bulgaria

E-mail address: angelov.vl@gmail.com sage techniques to influence the lymph system $[2,3,7,8]$. The massage therapy is defined as older than recorded time. The rubbing is considered as the primary form of medicine until the pharmaceutical revolution of the 1940s. Popularized again as part of the alternative medicine movement, massage therapy has recently received empirical support for facilitating growth, reducing pain, increasing alertness, diminishing depression, and enhancing immune function [2].

This study combines several issues in regard to massage therapy, sports and technological development. First, the literature review confirms that the massage therapy has extensive application as rehabilitation means for eliminating painful symptoms, for increasing the range of motion $[1,4,10-14]$ and in sports performance [4,11,15-19]. Second, the technological development in recent years, allows ex- 
tending the possibilities of influence in the field of massage therapy. Third, the relaxation is an important element of the restorative processes accompanying the training process. Muscle releasing is a trait of the muscle function. It is related to motor coordination. Thus, unifying these three problems has formed the main idea of this study. Our attention was focused on the examination of the effect of combining restorative massage with additional impact through relaxing audio-video as a way for more efficacious relaxation.

According to the hypothesis of the study, the application of the visualization through stereoscopic glasses during the massage therapy will increase the relaxation effect of the massage.

The aim of this paper was the investigation of the relaxation effect after sports restorative massage in standard conditions and in conditions with additional impact by using relaxing 3D VR video through stereoscopic glasses. The supplementary purpose of the research was the study of the effect of the additional visualization during the massage therapy on the pain symptoms of athletes with musculoskeletal problems.

The object of the study was the relaxation level and the back pain of the participants. The choice of the relaxation as a main object of the article was made by reason of the significance of this problem. On this basis, the subject of the study was the heart rate, the back skin folds, and the subjective sensations of the athletes.

\section{METHODS}

The contingent of the study was 25 Bulgarian students from the National Sports Academy. The age of the participants was 22-28 years old. The composition of the study participants included 10 women and 15 men. The athletes have been practicing different kinds of sport like track and field events, football, basketball, volleyball, badminton and wrestling. The study participants were not specifically selected. The study was implemented for one month, from 1st to 31st March 2018.

The study had three conditions. The first condition included initial registration of the heart rate (HR) of every participant at rest, performance of the massage procedure in standard conditions and final HR fixation (Figure 1a). The

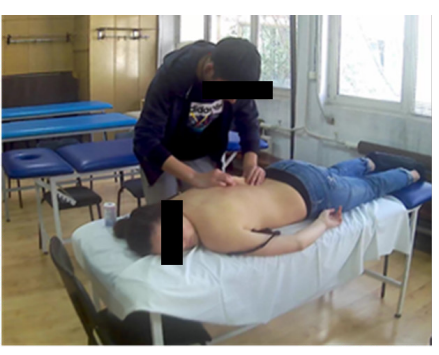

(a)

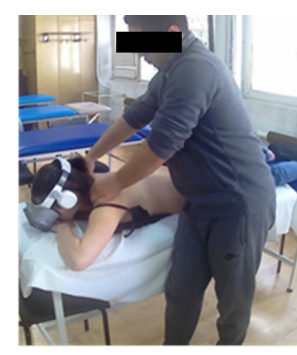

(b)
Figure 1. A restorative sports massage of the back in normal conditions (a) and with the usage of the VR glasses (b) second condition contained initial HR measurement, combined massage with additional impact of relaxing 3D VR video through stereoscopic glasses and final HR measurement (Figure 1b). The duration of each massage procedure in both conditions was 45 minutes. For comparison, the information from the literature review shows that similar studies use different duration of massage procedure: $15,30,40$, 45 and $60 \mathrm{~min}[28,30,34,36]$. A restorative sports massage was used for the needs of the study. The specific location of this massage was muscles and muscles groups of the back, upper and lower limbs. Each massage procedure included an impact on these three segments. In the third condition, a musculoskeletal state assessment of the participants was made. On this basis, the contingent for investigation of the influence of relaxing $3 \mathrm{D}$ VR video on the pain symptoms was defined.

The restorative massage applied the indicated methods in the following sequence: smoothing, squeezing, friction, squeezing, strong friction, squeezing, continuous vibrations, squeezing, and smoothing (Figure 2). It is obvious that the squeezing technique had an emphasized place in the recreation massage therapy applied to the study - about 50c/o of the total time.

A video processing of the $3 \mathrm{D}$ VR video files for the needs of the study was done. The created video files contained nature pictures and sounds, kaleidoscopes with different colors and other relaxing influences. The duration of the created video files was equal to the massage procedure time.

Stereoscopic glasses working with a smartphone were used as additional means for increasing the relaxing effect. The specifications of the device are the following: brand BOBOVR, model Z5, type VR headset, and compatible with smartphones with size 4.7-6.2 inch. This VR glasses are with autonomous headphones that allow the more concentrated audio impact. The brand of the smartphone used is Samsung J7. The video resolution of the smartphone is FHD and allows for high quality video.

The following scientific methods were used for the needs of the study: pedagogical observation, pedagogical experiment, survey and statistical methods.

To accomplish the main purpose of the study, the measure procedures included HR measurement (beats per minute) and self-rated state of relaxation. To complete the sup-

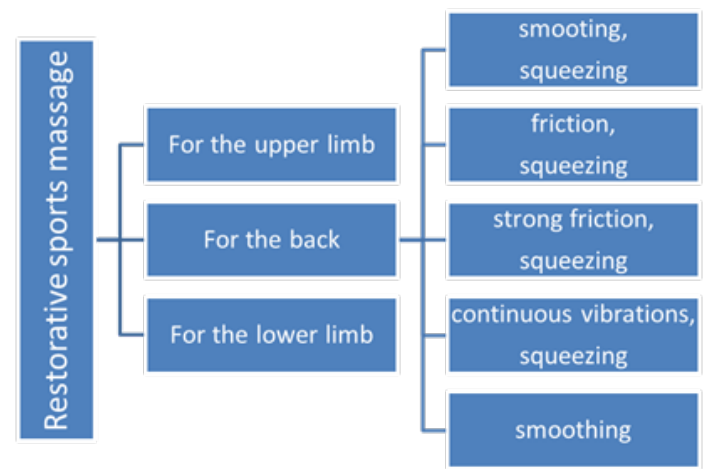

Figure 2. Classification of the techniques of the restorative massage 


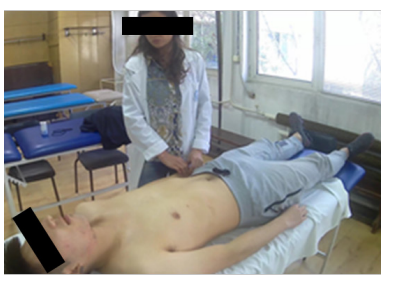

(a)

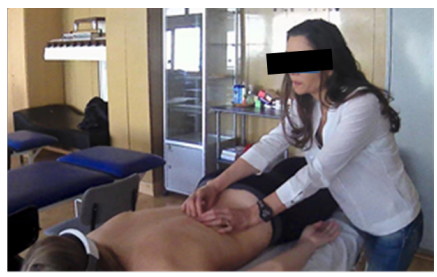

(b)

Figure 3. Measure procedures of the study - HR measurement (a) and skin fold assessment test (b)

plementary purpose of this study, were used the skin fold lift test and the visual analog scale. Also, the comments of the athletes about their pain sensations have been reported.

The heart rate measure procedure was manually accomplished with the help of chronometer model MAS-JS-9003, maker JUNSO (Figure 3). The number of the heart beats per minute was fixed to each participant while lying on the back (Figure 3). The subjective evaluation of the relaxation state was established using a survey with pre-formulated response variants. The participants were asked to give the answers that corresponded to their relaxation level. The survey contained questions about self-assessment of mental, emotional and muscular tension. A 4-degree scale was used for each question: Grade 1 - high tension, grade 2 - medium tension, grade 3 - low tension, grade 4 - no tension.

We used a visual analogue test with 10 numeric horizontal scales and skin fold lift test to objectify the data from the functional study. These tests were performed through palpation and pain intensity assessment of the subjective sensations of the participants surveyed. For a practical convenience in analyzing the results, we grouped the assessments from the visual analogue scale (VAS) as follows: grade 1 absence of pain, score 0 ; grade 2 - mild pain, score from 1 to 3 ; grade 3 - moderate pain, score from 4 to 6 ; grade 4 - severe pain, score from 7 to 10.

The study of the skin fold was accomplished on the basis of the results of the VAS. During the skin fold lift test, the resistance of the skin in the affected of the trigger point's zone of the back and the pain sensation from the performing test were assessed. The collected data was evaluated by using a four degree scale. Grade 1 - no resistance and no pain, grade 2 - a little resistance and a weak pain, grade 3 - with resis- tance and strong pain, plus orange peel skin type, grade 4 - no skin folds and very strong pain.

The measurement was implemented in the following conditions: ambient temperature - $23^{\circ}$, humidity - $35 \mathrm{c} / \mathrm{o}$, and high skill level of the therapist.

\section{Statistical Analysis}

The collected data was statistically processed and analyzed. The computer program SPSS Statistics 17.0 was used for this purpose. First, a descriptive analysis was done (mean, standard deviation). Second, Shapiro-Wilk test was used to determine normality of data distribution. Third, a comparison of the variables with Paired-Samples T Test for dependent samples was made. We have considered p-values $<0.001$ as statistically significant.

The descriptive analysis showed that the variation coefficient $(\mathrm{V})$ in all variables studied is between 6-13\%. Hence, the conclusion is that the sample is with a normal data distribution. Furthermore, the pedagogical experiment was based on a single studied group. On this basis, only the t-criterion of Student for dependent samples was used for the needs of the study.

\section{RESULTS}

The results are shown in Tables 1 and 2. All of the results are with an extremely statistical significance.

Table 1 shows the results of the descriptive analysis. It includes data on the age and the sex of the participants and the established heart rate at the various conditions of the study. The heart rate of each participant is measured before a massage procedure, after a restorative massage, and after a restorative massage in combination with the use of the stereoscopic glasses to complement the massage effect with $3 \mathrm{D}$ relaxing audio-video. The indicators surveyed were established for all participants and separately, for men and women.

Table 2 illustrates the statistical significance of the variables studied. The values of the absolute growth (d), the relative growth $(\mathrm{d} / \mathrm{o})$ and the probability values of the differences ( $\mathrm{p}$-values) are shown.

Figure 4 shows the standard deviation values of the heart

Table 1. Results from the descriptive analysis.

\begin{tabular}{|c|c|c|c|}
\hline Parameters & Participants & Mean & Standard deviation \\
\hline \multirow{3}{*}{ Age (years) } & Overall & 24.2 & 1.7 \\
\hline & Men & 24.0 & 1.4 \\
\hline & Women & 24.5 & 2.0 \\
\hline \multirow{3}{*}{$\begin{array}{c}\text { Initial HR } \\
\text { measurement (beats/min) }\end{array}$} & Overall & 74.4 & 8.2 \\
\hline & Men & 75.2 & 7.5 \\
\hline & Women & 73.1 & 9.5 \\
\hline \multirow{3}{*}{$\begin{array}{l}\text { HR measurement after massage in normal } \\
\text { conditions (beats/min) }\end{array}$} & Overall & 65.7 & 6.3 \\
\hline & Men & 66.6 & 6.2 \\
\hline & Women & 64.4 & 6.5 \\
\hline \multirow{3}{*}{$\begin{array}{l}\text { HR measurement after massage with 3D VR } \\
\text { glasses usage (beats/min) }\end{array}$} & Overall & 57.6 & 4.5 \\
\hline & Men & 58.9 & 4.7 \\
\hline & Women & 55.5 & 3.3 \\
\hline
\end{tabular}


Table 2. Results from the comparison of the differences of the variables and Statistical significance.

\begin{tabular}{|c|c|c|c|c|}
\hline Influences & Participants & $\mathrm{d}$ & $\mathrm{d} \mathrm{c} / \mathrm{o}$ & p-values \\
\hline \multirow{3}{*}{$\begin{array}{c}\text { After massage in normal } \\
\text { conditions }\end{array}$} & Overall & -8.7 & -11.7 & $<0.001$ \\
\hline & Men & -8.6 & $-11,4$ & $<0.001$ \\
\hline & Women & -8.7 & -11.9 & $<0.001$ \\
\hline \multirow{3}{*}{$\begin{array}{l}\text { After massage with 3D VR } \\
\text { glasses usage }\end{array}$} & Overall & -16.8 & -22.6 & $<0.001$ \\
\hline & Men & -16.3 & -21.7 & $<0.001$ \\
\hline & Women & -17.6 & -24.1 & $<0.001$ \\
\hline \multirow{3}{*}{$\begin{array}{l}\text { Difference between the } \\
\text { growth of the two impacts }\end{array}$} & Overall & -8.1 & - & $<0.001$ \\
\hline & Men & -7.7 & - & $<0.001$ \\
\hline & Women & -8.9 & - & $<0.001$ \\
\hline
\end{tabular}

Note: Values are: $\mathrm{d}$ - absolute growth; $\mathrm{d}$ c/o - relative growth; p-values - calculated probability values of the differences.

rates (beats per minute) for the various subjects in the three conditions of the study: initial, after a massage procedure, and after a combination of massage and relaxing 3D audiovideo through stereoscopic glasses.

\section{DISCUSSION}

The key findings of this study are in regard to the effect of combined impact of a restorative massage and $3 \mathrm{D}$ relaxing audio-video through VR glasses on the relaxation level of the athletes and the pain symptoms of the participants with musculoskeletal problems.

The positive physiological effect of the restorative massage is well-known $[10,11,17,18,20-22]$. The application of this type of massage procedure leads to regulation of the processes in the cerebral cortex, to normalization of the blood and lymph circulation, to acceleration of the metabolic processes, the tissue nutrition and oxygen supply, to recovering and improving of the working capacity.

In some of the reviewed literature sources, the authors compare the effect of massage therapy with the effect of relaxation therapy and their impact on musculoskeletal pain $[20,23]$. Other authors investigate the influence of manual massage on muscle relaxation through evaluation of trunk flexion [24]. In one study, the relaxing effect is achieved by using relaxation tape recordings [23]. Three main outcome measures are achieved: self-rated health, mental energy, and muscle pain. In other study the effect of the two types of therapies was realized by the authors through assessment of the saliva cortisol (stress hormones) level,

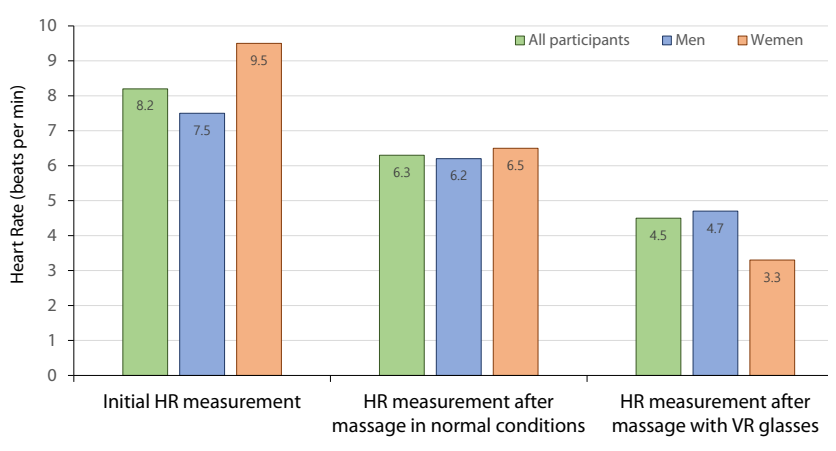

Figure 4. Standard deviation values of the heart rate in the different conditions of the study mood, anxiety level, neck, shoulder and back pain, range of motion including neck extension and shoulder abduction [20]. In another reviewed literature source, the authors analyze effectiveness of massage therapy by using the heart rate together with other indicators like state anxiety, blood pressure, mood, assessment of pain, and cortisol level [25].

The main task of this study was to compare the relaxing effect of restorative sports massage with the combined effects of massage and 3D relaxing audio-video through stereoscopic glasses. An additional task is the investigation of the mentioned two types of the influences on the pain symptoms of the participants. On this basis, we have chosen the heart rate and the subjective sensations as indicators for determining the level of relaxation. The skin fold lift test, the visual analog scale, and the pain sensation survey were used to determine the effect of the influences on the lower back pain reduction. During the research of the literature, we found many references that use the heart rate as an indicator for assessment the effect of different massage therapies [25-36]. In these studies the effectiveness of massage therapy was analyzed through HR together with complementary parameters. As example, the purpose of one of commented studies is to determine whether massage significantly reduces anxiety, pain, and muscular tension and enhances relaxation compared with an equivalent period of rest time after cardiac surgery [26]. In other study the aim was to investigate the immediate effects of traditional Thai massage on stress-related parameters including heart rate variability, anxiety, muscle tension, pain intensity, pressure pain threshold, and body flexibility in patients with back pain associated with myofascial trigger points [36]. The research approach in our study has some similarity to the idea of a reviewed study, which aimed to investigate possible effects of mechanical massage and mental training through heart rate, blood pressure and fingertip temperature measurement [33]. Thus, from the discussed literature it can be concluded that heart rate is a widely used parameter for assessing the effect of different types of massage.

Another argument about the decision for the assessment of the relaxation level with the help of HR measurement and the evaluation of the subjective sensations was dictated by their easy and timely application. The results obtained are processed and analyzed quickly and easily. It is known 
that many external factors affect the heart rate. This fact is not particularly important in this research, because the aim is to determine and compare the differences of the values of this indicator established in each condition of the study. The focus is not on the objectivity of the values, because the HR depends on various external factors. Furthermore, the impacts applied during the study were performed under exactly the same environmental conditions: temperature, humidity, noise background, lighting, etc.

The study established that the average value of the participant's age was 24.2 years. On the basis of three comparisons, the results from the two impacts of the study were analyzed. It was expected that the relaxing effect from the application of the restorative sport massage will be established. The heart rate variation before the massage $(74.4 \mathrm{bpm})$, after the massage procedure in normal conditions $(65.7 \mathrm{bpm})$, and after the massage with additional 3D VR visualization (57.6bpm) was defined with the help of the descriptive analysis of the results (Table 1, Figure 4). For confirming the hypothesis of the study, first, the growth between the initial and the final HR after the massage in standard conditions was defined $(-11.7 \mathrm{c} /$ $\mathrm{o} ; \mathrm{p}=0.001)$. The result obtained is statistically significant. The detected heart rate delay was expected. It is the result of the nature of the massage procedure used. Similar results are described in some of the studies cited in the literature review [26,28-34]. Second, the increase between the initial and the final HR after the massage with the usage of the stereoscopic glasses was calculated $(-22.6 \mathrm{c} / \mathrm{o} ; \mathrm{p}=0.001)$. The statistically significant result again impresses. The use of additional relaxation with VR glasses combined with the massage procedure, leads to a significant delay in heart rate. On this basis, it can be concluded that the relaxation level is also increased. Third, the difference between the growths of the two impacts was found $(-8.1 \mathrm{bpm} ; \mathrm{p}=0.001)$. The established results were in favor of the new impact. It is obvious from the percentage growth, that the relaxing effect from the combined influence of the restorative massage and $3 \mathrm{D}$ VR visualization was twice increased. The analysis of the collected data was completed with relation founded between the results of the men and the women (Figure 4). It appears that the level of relaxation is similar in the both sexes in all stages of the study. Nevertheless, the results of the women were slightly better than of the men. It is important to be mentioned that the subjective sensations of all participants were 100c/o positive regarding the use of the $3 \mathrm{D}$ visualization through the stereoscopic glasses during the massage procedure. All of the athletes examined stated in the survey that they had achieved a better quality of relaxation after the new impact. This fact can be explained as a result of the accumulation of impacts that have a relaxing effect. Performance of a restorative massage only, leads to muscle releasing. Combining this massage with the additional impact through virtual reality glasses increases the total relaxation effect. The declared feeling of a high level of relaxation by the participants surveyed can be explained by the deeper and more comprehensive impact through the new approach. The use of $3 \mathrm{D}$ relaxing video in combination with the massage procedure helps to increase the relaxation in its three main levels - muscular, emotional and mental.

In the next stage of the study, a skin fold lift test was applied before and after the restorative massage in both types of conditions during the massage procedure: standard and with $3 \mathrm{D}$ visualization by stereoscopic glasses. At the beginning of the test, five participants have been diagnosed with resistance and strong pain in the lumbar spine (grade 3). After a restorative massage under normal conditions, we found less resistance and weaker pain (grade 2). During and after the audio visualization through the virtual reality glasses, painful symptoms were not observed. The lack of pain during the rehabilitation massage with audiovisuals, allowed us to apply massage techniques to reduce tissue resistance and restore the skin's mobility towards underlying tissues.

The explanation for the positive result found in the two studied directions can be based on the physiological processes in the brain. It can be assumed that the application of the $3 \mathrm{D}$ visualization through stereoscopic glasses with relaxing influence during massage therapy leads to a balance of the cerebral cortex processes and this is the reason for the increased releasing effect of the restorative massage and for the reduction of the pain symptom to athletes with established musculoskeletal problems.

The study is limited by factors such as age, education, social and health status, sports qualification. Furthermore, the analysis of the results is not bound with the nature of the sport practiced by the participants. As an additional limit, the size of the sample and the duration of the study can be defined. Another limitation of the study is the absence of a device which is able to measure relaxation. Extending these limits in further researches of this nature, will allow to draw more general and categorical conclusions regarding the effects found in this study.

\section{CONCLUSIONS}

The study confirmed that the hypothesis of the paper is correct. This allowed concluding that the usage of the modern multimedia means can be combined successfully with massage therapy for better results.

The positive results found give us a reason for the extension of the study. In further researches the number of the participants of different ages and with various sports qualification will be investigated. The combined effect of the tonic massage and appropriate 3D VR visualization will be investigated. Another possibility to extend the study is to provide a sufficient contingent of athletes with established musculoskeletal problems to prove the statistical significance of the positive effect of the $3 \mathrm{D}$ VR visualization on the pain symptoms. 


\section{ACKNOWLEDGEMENTS}

The research was carried out on a scientific project funded by the National Sports Academy "Vasil Levski", Sofia, Bulgaria.

\section{Conflicts of Interest}

The authors declare no conflict of interest.

\section{REFERENCES}

1. Cherkin D, Eisenberg D, Sherman K. Randomized trial comparing Traditional Chinese Medical Acupuncture, Therapeutic massage, and Self-care educational for chronic low back pain. Arch Intern Med. 2001; 161:1081-1088.

2. Field TM. Massage therapy effects. Am Psychol. 1998; 53:1270-1281.

3. Goats GC. Massage-the scientific basis of an ancient art: Part 1. The techniques, Br J Sports Med. 1994; 28 (3):149-152.

4. Gotova Z. Chinese traditional methods of treatment the acute low back pain in gymnasts. SSA Sci J. 2014; 137 139.

5. Irnich D, Behrens N, Molzen H. Randomized trial of acupuncture compared with conventional massage and 'sham' laser acupuncture for treatment of chronic neck pain. BMJ 2001; 322:1-6.

6. Namikoshi T. The Complete Book of Shiatsu Therapy. Health \& Harmony, 2008.

7. Netchanok S, Wendy M, Marie C. The effectiveness of Swedish massage and traditional Thai massage in treating chronic low back pain: a review of the literature. Complement Ther Clin Pract 2012; 18:227-234.

8. Terrier JC. Technik der manipulativmassage. Ebert-Verlag, 1995.

9. Yang Ji-zhou. The Great Compendium of Acupuncture and Moxibustion. Beijing, China. People's Medical Publishing House, 1997.

10. Braverman D, Schulman R. Massage techniques in rehabilitation medicine. Phys Med Rehabil Clin N Am. 1999; 10(3):631-649.

11. Brummitt J. The role of massage in sports performance and rehabilitation: current evidence and future direction. N Am J Sports Phys Ther. 2008; 3:7-21.

12. Cherkin D, Sherman KA. Comparison of the effects of 2 types of massage and usual care on chronic low back pain. Arch Intern Med. 2011; 155:1-9.

13. Hernandez-Reif M, Field T, Krasnegor J. Lower back pain is reduced and range of motion increased after massage therapy. Int J Neurosci. 2001; 106:131-145.

14. Pope MH, Phillips RB, Haugh LD, et al. Prospective randomized three-week trial of spinal manipulation, transcutaneous muscle stimulation, massage and corset in the treatment of subacute low back pain. Spine (Phila
Pa 1976). 1994; 19(22):2571-2577.

15. Cafarelli E, Flint F. The role of massage in preparation for and recovery from exercise. Sports Med. 1992; 14(1):1-9.

16. Gotova Z. Treatment and prevention of injuries in the lumbar spine in elite gymnasts. Sport Sci. 2012; 458461.

17. Gotova Z. Tracking the effect of application of restorative massage to athletes with disabilities. Sport Sci. 2016; 2:108-111.

18. Hemmings B, Smith M, Gradon J, et al. Effects of massage on physiological restoration, perceived recovery, and repeated sports performance. Br J Sports Med., 2000; 34:109-115.

19. Weerapong P, Hume P, Kolt G. The mechanisms of massage and effects on performance, muscle recovery and injury prevention. Sports Med. 2005; 35:235-256.

20. Leivadi S, Hernandez-Reif M, Field T, et al. Massage therapy and relaxation effects on university dance students. J Dance Med Sci. 1999; 3(3):108-112.

21. Nordschow M, Bierman W. The influence of manual massage on muscle relaxation: effect on trunk flexion. J Am Phys Ther Assoc. 1962; 42(10):653-657.

22. Tiidus P. Manual massage and recovery of muscle function following exercise: a literature review. J Orthop Sports Phys Ther. 1997; 25:107-112.

23. Hasson D, Arnetz B, Jelveus LA. Randomized clinical trial of the treatment effects of massage compared to relaxation tape recordings on diffuse long-term pain. Psychother Psychosom. 2004; 73:17-24.

24. Nordschow M, Bierman W. The influence of manual massage on muscle relaxation: effect on trunk flexion. J Am Phys Ther Assoc. 1962; 42 (10):653-657.

25. Moyer CA, Rounds J, Hannum JW. A meta-analysis of massage therapy research. Psychol Bull. 2004; 130:3-18.

26. Braun LA, Stanguts C, Nurs B, et al. Massage therapy for cardiac surgery patients - a randomized trial. J Thorac Cardiovasc Surg. 2012; 144(6):1453-1459.

27. Meftahi N, Bervis S, Taghizadeh S, et al. The Effect of Lying in Prone Position on Blood Pressure and Heart Rate with and without Massage. JRSR 2014; 1(2):40-43.

28. Kaye AD, Kaye AJ, Swinford J, et al. The Effect of Deep-Tissue Massage Therapy on Blood Pressure and Heart Rate. J Altern Complement Med. 2008; 14(2):125128.

29. Chompoopan W, Eungpinichpong W, Eungpinichpong W. Effects of Traditional Thai Massage on Heart Rate, Blood Pressure, and Anxiety in Depression Patients: A Pilot Study. Int J Geom. 2016; 11(28):2892-2895.

30. Pinar R, Afsar F. Back Massage to Decrease State Anxiety, Cortisol Level, Blood Prsessure, Heart Rate and Increase Sleep Quality in Family Caregivers of Patients with Cancer: A Randomised Controlled Trial. Asian Pac J Cancer Prev. 2015; 16(18):8127-8133.

31. Pystupa TD. Effect of Partial Sports Massage on Blood Pressure and Heart Rate. Phys Ed Stud 2013; 6:55-58.

32. Supa'at I, Zakaria Z, Maskon O, et al. Effects of Swedish 
Massage Therapy on Blood Pressure, Heart Rate, and Inflammatory Markers in Hypertensive Women. J Evid Based Complementary Altern Med. 2013; 1-8.

33. Muller J, Ekström A, Harlén M, et al. Mechanical Massage and Mental Training Programs Effect Employees' Heart Rate, Blood Pressure and Fingertip Temperature: An exploratory pilot study. Eur J Integr Med. 2016; 8(5): 762-768.

34. Paschoala MA. Influence of Classic Massage on Cardiac Autonomic Modulation. Fisioter Mov. 2016; 29(3): 487-496.
35. Toro-Velasco C, Arroyo-Morales M, Fernández-de-lasPeñas C, et al. Short-Term Effects of Manual Therapy on Heart Rate Variability, Mood State, and Pressure Pain Sensitivity in Patients with Chronic Tension-Type Headache: A Pilot Study. J Manipulative Physiol Ther. 2009; 527-535.

36. Buttagat V, Eungpinichpong W, Chatchawan U, et al. The Immediate Effects of Traditional Thai Massage on Heart Rate Variability and Stress-Related Parameters in Patients with Back Pain Associated with Myofascial Trigger Points. J Bodyw Mov Ther. 2011; 15:15-23. 